\title{
El cine chileno y su discurso sobre lo popular. Apuntes para un análisis histórico
}

\section{The chilean cinema and his popular discourse. Notes on an historical analysis}

\author{
Eduardo Santa Cruz A. \\ Universidad de Chile \\ esantacr@uchile.cl
}

\section{Resumen}

El presente texto se centró en el análisis del tipo de discursividad sobre y hacia lo popular producido y difundido por el cine nacional de ficción, especialmente desde los años '90 en adelante. Sin perjuicio de lo anterior y más bien como necesidad impuesta por la óptica analítica escogida, se intenta rastrear dicho desarrollo discursivo desde los orígenes de la producción cinematográfica de ficción en nuestro país, aunque, valga aclararlo, sin ánimo de reconstrucción cronológica, sino más bien tratando de mostrar cómo la discursividad del cine recogió, en contextos diversos, las versiones discursivas mayores sobre lo popular y lo nacional que se manifestaron a lo largo del siglo XX.

Palabras clave: Cine chileno, cultura de masas, cultura popular, historia cultural

\begin{abstract}
The present text was centered in the kind of analysis about and towards the discoursivity of the popular, produced and broadcast by the fictional national cinema, specially since the '90s and forwards. Despite the previous, and more as a necessity imposed by the elected optic of analysis, it tries to trace this discourse development since the origin of the fictional cinematographic production in Chile, eventhough, we must clarify, that there is no an intent of a chronological reconstruction, rather more an intent to show how cinema discoursivity collect, in diverse contexts, global discoursivity versions about the popular and the national theme, that was expressed during the XXth century.
\end{abstract}

Keywords: Chilean cinema, Mass culture, Popular culture, Cultural history 
1.

De manera similar a lo ocurrido en otros países latinoamericanos, en nuestro país la llegada del cine como otra alternativa de espectáculo en el contexto de procesos modernizadores que significaron la aparición de las primeras manifestaciones de un mercado y una industria cultural, motivó los primeros intentos de realizaciones nacionales (King, 1994; Paranagua, 2003). Se trataba en un comienzo de las llamadas vistas, películas de algunos minutos que registraban alguna actividad social, hecho político, eventos o acontecimientos de interés general, de producción nacional ${ }^{1} \mathrm{o}$ importadas desde el extranjero, especialmente de origen europeo $^{2}$.

En el período del llamado cine mudo, desde 1910, año en que se produce el primer film argumental chileno, Manuel Rodríguez, hasta 1931, se filmó la no despreciable suma de 81 películas de este tipo, dos documentales y dos películas de dibujos animados. Cabe señalar que el primer largometraje se realizó en 1916 y fue La Baraja de la Muerte (o El enigma de la calle del Lord). ${ }^{3}$

Si bien no logró consolidarse plenamente una industria cinematográfica ${ }^{4}$, la producción nacional marcó algunas tendencias que se seguirían manifestando en décadas posteriores. En primer término, cabe señalar lo que dice relación con una perspectiva nacionalista e identitaria. Hacia los años'20 ya es posible detectar la existencia de un entorno cultural y comunicacional, no solamente en Santiago, en el que y desde el cual circulan un conjunto de estrategias discursivas que apuntan a la construcción de un sentido común y un imaginario de país y sociedad. Y ello en un contexto social, económico y político que va crecientemente siendo marcado por la sensación de crisis y agotamiento del modelo de sociedad y de su patrón de

1. Se dice que la primera de ellas fue la titulada Carreras en Viña, exhibida en el Teatro Apolo, de Viña del Mar en 1900, aunque la falta de datos y registros hace que se considere la primera película nacional, el corto de tres minutos Un ejercicio general de bombas, estrenado el 26 de mayo de 1902 en el Teatro Odeon de Valparaíso. Durante la primera década siguieron produciéndose estas filmaciones, las que tuvieron especial auge con ocasión de las fiestas del Centenario en 1910.

2. Estas fueron mucho más numerosas y la atracción que despertaban puede verificarse por el hecho de que, por ejemplo, la revista Sucesos anunciaba en 1903 la llegada de un barco con ocho tambores de vistas desde Buenos Aires, para ser exhibidas en el Teatro Victoria, de Valparaíso. Algunos títulos: La corrida de toros, La guerra en Sudáfrica, La coronación de Eduardo VII, Los funerales de Emilio Zolá, etc., todas ellas exhibidas en 1905, en el Teatro Nacional, de Santiago.

3. Esta película es el primer largometraje argumental chileno, con argumento del poeta y periodista colombiano Claudio de Alas, inspirado en el llamado crimen de la Legación Alemana, que conmocionó la sociedad santiaguina y fue el primer caso de censura de un film nacional. La Municipalidad de Santiago prohibió su exhibición arguyendo que el crimen aún estaba siendo juzgado en los Tribunales. Más tarde, fue estrenado en el Teatro Colón, en Valparaíso.

4. Hubo, sin embargo, varios intentos en la capital y otras ciudades por crear empresas consagradas a la producción de películas. Entre ellas, Chile Film, creada por el precursor Salvador Giambastiani en 1915; la Hans Frey Co., en Valparaíso en 1917; la Condor Film, en Valdivia en 1915; la Vack Film S.A. en 1922, etc. 
desarrollo. Un componente importante que cruza transversalmente dichas discursividades es el nacionalismo.

Para efectos de nuestro texto, lo que hay que destacar es cómo dicho ideario era vivido más como sentimiento, a nivel del sentido común colectivo. Desde fines del siglo XIX, el propio aparato educacional naciente y colocado en las coordenadas racionalistas y positivistas que le daban sus modelos europeos, no fue ajeno a la difusión y reproducción de ese sentimiento nacional. En lo coyuntural, la prolongación de los conflictos de límites con Argentina que llevaron casi a la guerra al terminar el siglo XIX y la no resolución definitiva de los mismos temas con Perú, crearon condiciones para que, a nivel masivo, un nacionalismo agresivo y chovinista se mantuviera a flor de piel. Por otro lado, contribuyó a su extensión en el cuerpo social medio y popular la percepción difundida a comienzos del siglo XX (y no sin correlato empírico) de una elite extranjerizada en sus pautas culturales y ajena e indiferente frente a los problemas nacionales. La industria cultural naciente a comienzos del siglo XX, especialmente a nivel de la prensa escrita, si bien responde en su desarrollo a los patrones universales de la sociedad capitalista moderna, incorpora a ese nacionalismo no sólo como temática específica, sino como un discurso que recorre licuadamente al interior de sus distintos géneros y formatos.

En el caso del cine, títulos como La Agonía de Arauco y Alma Chilena (1917); Todo por la Patria (1918); Manuel Rodríguez, otra vez (1920); Elempuje de una raza (1922); Hombres de esta tierra, Por la razón o la fuerza y Corazón de Huaso (1923); Martín Rivas, Nobleza Araucana, Las aventuras de Juan Penco boxeador, Como Don Lucas Gómez y El Húsar de la Muerte (1925), entre otras, nos hablan de la importancia que tuvo esta línea productiva. Sin embargo, autores como Rinke (2002) hacen ver que junto a ella convivió una tendencia más universal que trabajó en géneros y temáticas que la industria hollywoodense había popularizado. Es el caso de películas de acción como El Hombre de Acero (1917) o Traición (1923), la cual contemplaba escenas de acción filmadas en elEdificio Ariztía ${ }^{5}$, e incluso lo que dicho autor denomina westerns chilenos, como El Leopardo (1926) o Justicia del desierto (1926), entre otros. En esta misma línea ubica las producciones de dibujos animados, como Vida y milagros de Don Fausto, celebrada caricatura que apareció durante décadas en el diario El Mercurio.

Durante este período es posible afirmar que predominan temáticas que dicen relación con la exaltación patriótica de ciertos episodios o momentos históricos, especialmente la entonces cercana Guerra del Pacífico o la Independencia, en este caso fundamentalmente en torno a la figura legendaria de Manuel Rodríguez $z^{6}, y$, por otra parte, ubicadas en contextos costumbristas generalmente campesinos, como lugar de manifestación de la pureza de la esencia de la nacionalidad. Sin embargo, al juicio posterior, esto

5. Elllamado Edificio Ariztía, aún existente en la esquina de las calles Nueva York y La Bolsa fue construido en 1921 y considerado el primer rascacielos de Santiago. Era de propiedad del acaudalado senador y ex -alcalde de Viña del Mar, Rafael Ariztía. El edificio constaba de diez pisos más una torre y lucía ascensores y calefacción central.

6. Abogado, procurador de la ciudad de Santiago en 1811 y ministro de Guerra hasta 1814. Durante la Guerra de Independencia organizó grupos armados independentistas en el centro del país (N. del E.) 
...estuvo lejos de ser un cine nacional que intentara interpretar y plasmar en imágenes la difícil y rica etapa que les tocó vivir: los vaivenes económicos provocados por las crisis salitreras, los estallidos sociales, los problemas limítrofes con el Perú, la institucionalidad quebrantada por las asonadas militares, el desprecio y resentimiento entre sus clases sociales y el quiebre de un modo de ser con sus costumbres, valores y formas de vida. Nada de eso se reflejó en el cine, o al menos los intentos pasaron inadvertidos (Jara, 1994: 173-174).

Es posible que el reclamo de la autora citada no considere que la matriz conservadora en la base de la discursividad cinematográfica chilena de la época, justamente al considerar lo nacional como una esencia ahistórica, lo sitúa más allá de los contextos específicos y lo popular lo construye como un conjunto de costumbres y actitudes, naturalmente subordinadas, para configurar el estereotipo de lo popular sano, divertido e ingenioso, en suma, el infantilizado roto patriota, que muere heroicamente en la guerra, por oposición al roto alzado, insolente y rebelde, que cuestiona o resiste su dominio, figura que en el cambio de siglo se asoció a la acción del agitador extranjero, que venía a envenenar a un pueblo supuestamente sumiso y sano por naturaleza (Romero, 1997).

Más aún, en rigor, dicha perspectiva no es realmente contradictoria con su implantación en esquemas y formatos cinematográficos universales, como acertadamente lo acota Eliana Jara:

Aunque se explota a través del folletín, la comedia banal, los sentimientos patrios o una estereotipada visión del criollismo, fue un cine que buscó el aplauso fácil y la complicidad de un espectador poco exigente, intentando reproducir y copiar los modelos y convenciones venidos de fuera (Ibídem).

\section{2.}

A partir de los años 30, con el desarrollo del cine sonoro y en el marco del proceso modernizador desarrollista, el cine chileno vive una particular situación, en relación con la lógica predominante en la ampliación y crecimiento del mercado y la industria cultural. Si bien en la operación del sector encontramos diferentes actores, es abrumadoramente predominante la presencia de la iniciativa y propiedad privada, ya sea ésta bajo la forma de conglomerados capaces de controlar en el sentido fuerte un mercado, como sucedió con los diarios, o a través de la multiplicación de pequeñas empresas incluso familiares, como ocurrió en el caso de la radio. En ese sentido, es necesario llamar la atención hacia el hecho de que no encontramos una acción sistemática y de magnitud de parte del Estado, a pesar del rol protagónico e intervencionista con que actúa en otros ámbitos. Ni en la radio, la industria de la música y el espectáculo o la prensa escrita, es posible observar una acción estatal decidida y clara. Más bien se reduce a un papel regulador a nivel normativo (como la concesión de frecuencias radiales) o a efectos de regulaciones 
políticas generales (como las contenidas en las leyes sobre Seguridad Interior del Estado o la llamada Ley Maldita ${ }^{7}$.

Solamente en el caso del cine existió una política específica y que fue un total fracaso. En 1942, la flamante Corporación de Fomento de la Producción (CORFO) creó Chile Films, con la intención más o menos explícita de desarrollar la industria cinematográfica en el país. Recién dos años después se estrenó su primera producción, Romances de medio siglo, con mediocres resultados de crítica y de taquilla ${ }^{8}$. En los años siguientes, los resultados no fueron mucho mejores, a pesar de los cuantiosos recursos invertidos. Incluso en 1946 hubo un intento por exportar las películas de Chile Films, como ocurrió con El Padre Pitillo ${ }^{9}$, que fue exhibida en México, al decir de Mouesca y Orellana, "con un gran fracaso que entierra las posibilidades exportadoras de Chile Films” (1998). Incluso probó diversas fórmulas ${ }^{10}$, pero en 1949, tras el fracaso del film Esperanza, la CORFO terminó por clausurar el proyecto (Mouesca, 1997).

Mientras tanto y paralelamente, a partir de su propia iniciativa otros cineastas desarrollan una intensa actividad que transformó a la década de los 40 en una de las más prolíficas e importantes del cine nacional. Entre 1940 y 1949 se produjeron alrededor de cincuenta películas, muchas de las cuales tuvieron un gran éxito de público y pasaron a engrosar la lista de los clásicos del cine nacional. Para efectos del tema de los actores involucrados, digamos que la mayoría de esas películas se concentran en tres directores: José Bohr ${ }^{11}$, Eugenio de Liguoro y Jorge Délano "Coke". En 1941, se inauguraron dos empresas: los Estudios VDB (perteneciente a R.Vivado, E. de Liguoro y E. Baier) y los Estudios Santa Elena, de J. Délano y J. Spencer, estos últimos ubicados al entonces final de Av. Vicuña Mackenna, donde comenzaba el llamado Camino a Puente Alto. Ese mismo año se produce el mayor éxito comercial de la década del cine chileno, con la película Verdejo gasta un millón, basada en el personaje de Délano y en el programa radial Intimidades de la familia Verdejo, de Gustavo Campaña. Fue estrenada simultáneamente en Santiago, Valparaíso y Viña del Mar y dirigida por Eugenio de Liguoro, contó con la actuación de Malú Gatica, Romilio Retes y Alejandro Lira.

7. La ley de Defensa Permanente de la Democracia o ley maldita se promulgó en 1948 y proscribió al Partido Comunista chileno, impidiéndole participar en elecciones y derogando de sus cargos a alcaldes, regidores y parlamentarios comunistas (N. del E.).

8. La dirección estuvo a cargo del argentino, Luis Moglia y actuaron Inés Moreno, Francisco Flores del Campo y Nieves Yankovic, entre otros. Cabe destacar el hecho de que el libreto estuvo a cargo de los escritores Francisco Coloane y Carlos Vattier.

9. Dirigida por el también argentino Roberto de Ribbon, con la actuación de los actores de teatro Lucho Córdoba y Chela Bon y música de Nicanor Molinare.

10. En el mismo 1946 produjo La dama de la muerte, basada en un cuento de Robert L. Stevenson y ambientada en el Londres del siglo XIX y también Tormenta en el alma, basada en la obra teatral Fedora, del francés V. Sardou.

11. José Bohr produjo entre los 40 y 50 no menos de quince películas. Incluso tiene el record de haber hecho un film en trece días, El Relegado de Pichintún, comedia de mucho éxito de público, con libretos de Gustavo Campaña y las actuaciones de Ana González "la Desideria”, Rolando Caicedo y Alejandro Lira. 
De modo que junto al fracaso estatal, en los 40 hubo una interesante producción nacional en cine, la que sin embargo no llegó a configurar propiamente una industria. Los autores citados al respecto, en general coinciden en que un factor importante en ello fue la carencia de una política de fomento y apoyo al cine de parte del Estado, tal vez demasiado concentrado en sacar adelante su propio proyecto. Tal vez también ello motivó que en 1948 se creara la llamada Comisión Pro-defensa del Cine Chileno, formada por directores y cineastas. Durante algunos años, sin embargo, la producción nacional mencionada fue capaz de competir comercialmente con las películas norteamericanas, mexicanas y argentinas. Sin embargo, en los 50 la producción nacional disminuyó considerablemente hasta ser casi inexistente. En toda la década se hicieron 11 largometrajes. El debate público producido acerca de la situación del cine nacional llevó a que se presentara en el Parlamento, en 1956, por primera vez, un proyecto de ley sobre el fomento al cine nacional, obviamente sin resultados.

En todo caso, es en esta década cuando la producción nacional gira hacia otros ámbitos, comoporejemplola aparición en 1954 delNoticieroEMELCOqueibaregistrandosemanalmente la actualidad nacional; otro campo de desarrollo en los 50 fue la producción de documentales, como Caletones: ciudad del fuego, de Patricio Kaulen (1955); Trilla de Sergio Bravo y Andacollo de Jorge di Lauro, de 1958; Artistas plásticos chilenos, de Nieves Yankovic y Jorge di Lauro en 1959 y ese mismo año Casamiento de negros, sobre la cerámica de Quinchamalí, con música de Violeta Parra; Recordando, sobre la base de trozos de la filmografía nacional de principios de siglo, en 1960, etc., a lo cual habría que agregar la creación del Centro de Cine Experimental de la U. de Chile. Esta suerte de retirada del campo comercial fue transitoria. Muchos de los nuevos cineastas que se estaban formando en los años 50 fueron los protagonistas del llamado boom del cine nacional en las pantallas comerciales en la segunda mitad de los 60.

En este período desaparece casi completamente la temática referida a contenidos históricos, salvo el caso de Romance de medio siglo y Bajo un cielo de gloria, ambas de 1944, y se hace predominante justamente en los aludidos cineastas independientes el recurso a la comedia costumbrista para incorporar el mundo popular, preferentemente campesino. Es el caso de $E l$ hechizo del trigal, Hombres del sur y Dos corazones y una tonada, todas filmadas en 1939, o también Flor del Carmen (1944), Si mis campos hablaran (1947), Mis espuelas de platay Tonto Pillo, ambas de 1948. Esta última, junto con Rosita de Cachapoal (1952) son buenos exponentes de cómo estas producciones asumen la migración campo-ciudad, fenómeno explosivo en la década de los 40. Allí se presenta el contraste entre una identidad popular campesina que conserva la pureza, inocencia, generosidad, etc., valores que serían propios de la verdadera alma nacional y de un ambiente urbano en que predominan pseudo-valores modernos, más bien universales, marcados por el individualismo y la lucha y la competencia de todos contra todos.

Una cuestión interesante es que se aborda de manera explícita el tema de lo popular urbano, especialmente por parte de Jorge Délano, quien lleva al cine su personaje de Juan Verdejo, con Verdejo gasta un millón (1941) y Verdejo gobierna en Villaflor (1942). Por su lado, José Bohr lo hará con P'al otro la’o (1942), Uno que ha sido marino (1951) y especialmente El 
Gran Circo Chamorro (1955). Aquílo popular transita fundamentalmente por el modeloclásico universal del picaro, que manifiesta su habilidad para enfrentar las dificultades de la existencia a través del humor y una sabiduría natural, desprovista de toda potencialidad crítica y cuya irreverencia no trasciende los límites de una moralidad conformista. Se trata nuevamente de la imagen de lo popular subordinado, pero simpático y aunque colocado en los marcos de lo urbano y lo moderno, sin abandonar en lo fundamental la matriz identitaria conservadora tradicional.

Esta perspectiva se mantuvo presente durante el renacer de la producción nacional en los años '60, especialmente en los filmes dirigidos por Germán Becker, explícito propagandista de la discursividad más clásica y conservadora sobre lo nacional y lo popular. Utilizó el fomato del musical en Ayúdeme Ud. compadre (1968) y Volver (1969) y el de la comedia costumbirsta en Con el santo y la limosna (1971). Otro caso fue el de Alejo Alvarez con Tierra Quemada (1968) y El afuerino (1971), especies de western criollos. Finalmente, otras producciones en esta dirección fueron las últimas películas de José Bohr: Un chileno en España (1962) y Sonrisas de Chile (1969) y El burócrata González (1964), de Tito Davidson, entre otras.

Por otra parte, este período vio surgir por primera vez en la historia del cine nacional un tipo de producciones que se pueden inscribir en una perspectiva problematizadora de la matriz anterior, instalando una lectura crítica en que lo popular aparece al interior de lo que se percibe como una sociedad en crisis y en que es víctima de sus desigualdades e injusticias, pero fundamentalmente en que también es considerado el sujeto histórico del cambio social. En ese sentido,

El tratamiento que el cine hace de lo popular tiene, por tanto, dos rasgos significativos: primero, la identificación de lo popular con lo auténticamente nacional; segundo, la inclusión de esa identificación en el interior de un proyecto político revolucionario, mediante lo cual se excluían de la cultura popular los elementos tradicionales asociados al conservadurismo oligárquico y los elementos masivos asociados a la cultura estadounidense del star system. Si hay que buscar referentes anteriores para este cine ellos se encuentran, entre otros, en el neorrealismo italiano de postguerra (Salinas y Stange, 2006: 12).

En esa dirección, la temática y los géneros trabajados fueron diversos. La dura cotidianidad popular en Morir un poco, de Alvaro Covacevic, o Largo Viaje, de Patricio Kaulen, ambas de 1967; la dramática injusticia social en El Chacal de Nahueltoro, de Miguel Littin (1970); la revisión crítica de la historia nacional en Caliche Sangriento, de Helvio Soto (1969), pero también la emergencia de un nuevo sujeto social como era el segmento juvenil en New Love, de Alvaro Covacevic, o Lunes $1^{\circ}$, Domingo 7, de Helvio Soto, ambas de 1968, hasta la problemática explícitamente política de Voto más fusil, de Helvio Soto (1971), y Ya no basta con rezar, de Aldo Francia (1972), pasando por Tres tristes tigres, de Raúl Ruiz (1968).

Se trata de una mirada crítica que intentó también dar cuenta del proceso político que desemboca en el período de la Unidad Popular tratando de insertarse en términos generales en 
la discursividad clasista que concibe a lo popular, no sólo como depositaria de lo más auténtico de los elementos constitutivos de la nacionalidad, sino como el espacio y el actor portador de la misión histórica de reformular la sociedad y sus estructuras. Lo singular es que la vida cotidiana de lo popular, representada en diferentes personajes y situaciones, es leída en tanto claves de un sujeto colectivo dotado de conciencia, organización y proyecto.

\section{3.}

Si hay una imagen difundida a nivel de un cierto sentido común como el que vehicula la prensa, es la de un supuesto auge explosivo del cine chileno desde los años 90 en adelante. Sin embargo, como lo señala la bibliografía aparecida en el período, dicha imagen simplifica una situación mucho más compleja y que presenta más de alguna arista problemática. Contribuyen a esa visión, si se quiere triunfalista, dos hechos: por una parte, la remasificación del consumo de cine en salas ocurrido en la década de los 90 . Como es sabido, la asistencia de espectadores entró en una profunda crisis, especialmente desde 1973 en adelante, lo que afectó tanto al tradicional cine de barrio con sus funciones rotativas y programaciones múltiples, como a la sala del "centro" o el "barrio alto", con sus funciones fijas y su programación única, en el caso de Santiago, aunque el fenómeno tampoco fue extraño a las ciudades y pueblos de provincia. Basta señalar que a 1990 la cifra de salas de cine a nivel nacional se había reducido a noventa, siendo que la cifra histórica desde los años 20 del siglo pasado oscilaba entre dos y tres centenares.

Se generó así una imagen de una suerte de decadencia terminal, especialmente a raíz del auge de los videoclubes desde fines de los 80 y la aparición de la TV cable a principios de los 90, con su posibilidad de consumo doméstico de cine. Sin embargo, la instalación en el país de tres cadenas transnacionales: Cinemark, Hoyts y Showcase, produjeron un cambio significativo, no sólo a través de la recuperación de algunas de las antiguas salas y la construcción de muchas otras, sino promoviendo una nueva manera en la ritualidad propia de la asistencia al cine (Santa Cruz, 1999). Asimismo, utilizando nuevas estrategias de marketing y comercialización del espectáculo, en poco tiempo lograron que el cine nuevamente volviera a ocupar un sitial importante dentro de los espectáculos culturales públicos y masivos.

Hacia el año 2000, las tres cadenas controlaban el 90\% de las salas existentes en el país, las que llegaron en el 2003 a ser 229, con 68 mil butacas, es decir, recuperando el nivel histórico señalado antes. De igual forma, la asistencia de público se incrementó rápidamente, ya que en 1995 llegó a 5 millones de espectadores anuales y esa cifra se más que duplicó para el 2003 llegando a casi 12 millones (Salinas y Stange, 2006). Adelantemos del análisis que sigue el hecho que de esa cifra de público solamente un porcentaje que varía entre el $4 \%$ y el $14 \%$, según los años, corresponde a asistencia a películas chilenas.

En segundo término, cabe consignar que desde la década pasada, efectivamente se constata un crecimiento importante en la producción de películas chilenas, en lo que a largometrajes argumentales se refiere. Si bien no hay un registro exacto desde 1990 en adelante, tomando datos de distintas fuentes la cifra de largometrajes chilenos llegaría a cerca 
del centenar a la fecha $(\text { Trejo, 2000 })^{12}$, número no menor considerando, por ejemplo, que para el período 1910-1979 se consignaba la producción de 184 obras (Vega, 1979). Finalmente, a lo anterior se le debe añadir el hecho que unas pocas de esas producciones tuvieron un gran éxito de taquilla, lo que, entre otras cosas, eleva en algunos años el porcentaje de asistencia a películas chilenas muy por sobre la tendencia promedio.

Tras estas cifras, sin embargo, se ocultan algunos hechos fundamentales. El primero de ellos ya está insinuado. La importante recuperación de espectadores al cine como espectáculo público ha favorecido en poca medida a las películas nacionales, salvo unas contadas excepciones. Por otra parte, la producción cinematográfica se ha desarrollado al interior de una política cultural por parte del Estado y de unas transformaciones sociales y culturales generadas por el actual proyecto modernizador que es necesario precisar, aunque sea en sus rasgos centrales.

Es incuestionable que en nuestro campo cultural, el mercado es el eje articulador del mismo y el principal asignador de los recursos y la mayor parte de la producción cultural se dirige a mercados diferenciados de públicos masivos; en ellos se transa y se consume la cultura. La participación directa del Estado se ha expresado a través del desarrollo de fondos concursables; la construcción, implementación y gestión de centros culturales o limitadas políticas locales o sectoriales. Sin embargo, su empeño fundamental ha sido crear las condiciones para el desarrollo y crecimiento del mercado, cumpliendo el rol subsidiario propio del nuevo Estado liberal. El hecho de que sea el mercado el eje y motor dinamizador del crecimiento del campo cultural, ha implicado que la relación fundamental de la cultura cotidiana es con la industria cultural. El gasto estatal o de organismos privados no lucrativos (como universidades, embajadas, corporaciones, etc.) tiene una destinación, en estricto rigor, fundamentalmente elitista: una alta y pequeña burguesía ilustrada, intelectuales y cierto sector de estudiantes, que copan los centros culturales nuevos y ciertos barrios de la capital en que abundan teatros u otros locales de difusión cultural. Así, la política gubernamental ha dejado especialmente en manos de la industria cultural la producción dirigida a la mayoría de la población, es decir, no sólo los sectores populares, sino incluso extensos sectores medios y de la propia clase alta.

La inversión en publicidad, que es la principal fuente de recursos que maneja el mercado, se dirige, además, mayoritariamente hacia la televisión. Con ello, el círculo se cierra en términos de producir en el mercado cultural segmentaciones y especializaciones, marcadas por el signo de la exclusión y segregación, las cuales tienen como fundamento no sólo la disponibilidad de recursos monetarios para acceder a aquel (cuestión ya de por sí decisiva), sino que también el hecho de que la mayoría accede sólo a cierto tipo de productos culturales y no a otros. Con respecto al cine, Salinas y Stange señalan sobre las cifras de espectadores que asisten al cine anualmente, que

12. Al respecto, fuentes confiables son los registros que mantiene desde 1998 la Cámara de Comercio Cinematográfico. 
"Desagregados los datos por estratos socioeconómicos, se obtiene que casi el 70\% de los asistentes al cine corresponden a los sectores medioaltos y altos, el 37,5\% a sectores medios y menos del $6 \%$ a sectores bajos. Es decir, el cine de lo popular no tiene, en principio, lo popular como su público objetivo" (Salinas y Stange, 2006: 15).

En ese contexto, la acción subsidiaria del Estado sobre el cine chileno se ha plasmado fundamentalmente en la existencia de ciertos fondos concursables, desde la fracasada línea de créditos del Banco del Estado que operó entre 1992 y 1994, hasta los actualmente existentes, de la CORFO y el Consejo Nacional de la Cultura y las Artes. Se genera entonces una producción abigarrada, fragmentaria y dispersa financiada muchas veces parcialmente por concursos específicos y puntuales, que congregan cada año a una pléyade expectante de realizadores, especialmente jóvenes, a la espera de alcanzar el subsidio estatal, cuestión lograda obviamente por unos pocos. De este modo, difícilmente se pueden desarrollar proyectos de largo alcance, grupos de trabajo, líneas de producción, etc. En otros términos, el número no despreciable de largometrajes argumentales producidos en los últimos años no está dando cuenta, ni siquiera de manera embrionaria, del despuntar de una industria cinematográfica nacional, sino más bien de iniciativas individuales, las más de las veces inconexas, expresión de necesidades expresivas particulares, en algunos casos, y, en otros, de la repetición de ciertas fórmulas facilistas ya probadas de atracción de público (Villarroel, 2005; Estévez, 2005).

Esto último no es para nada de menor importancia. La concepción de que el apoyo estatal, vía fondos concursables, constituye un subsidio para facilitar la inserción de la producción nacional en el mercado cultural, de hecho favorece lo señalado en orden a que el realizador favorecido puntualmente por la ayuda estatal debe consolidar financieramente su obra en tanto éxito de taquilla, como única forma de encontrar los recursos para darle continuidad a su trabajo, o bien esperar a lograr ganar un nuevo concurso en la temporada siguiente. De esta forma, y adentrándonos en el tema específico de nuestra investigación, cabe recalcar lo señalado por los citados Salinas y Stange, en el sentido de que “...las películas sobre lo popular son "populares" también en términos de consumo” (2006). Efectivamente, las películas con gran éxito de público antes señaladas despliegan, de forma más o menos central, una discursividad sobre lo popular, en términos actuales o de lectura e interpretación del pasado. Pero, como vimos más atrás, esa "popularidad" no dice relación con una masividad popular que vaya al cine para verse a sí misma, como aconteció en el siglo pasado con el cine mexicano, por ejemplo (King, 1994), sino más bien con otros sectores sociales que ven reafirmadas sus percepciones y discursividades sobre lo popular.

En esa dirección, los autores citados concluyen en que

“... la representación del sujeto popular en el cine chileno del período (1997-2005) es una representación descriptiva, que concibe lo popular como un conjunto de atributos naturalizados, tomados del sentido común, con altos grados de componentes humorísticos y sexuales. Esta representación se realiza mediante la identificación de lo popular con ciertos 
estereotipos preconocidos por los espectadores, expurgándoles todo elemento político explícito o constitutivo" (Salinas y Stange, 2006: 36).

Coincidiendo en lo anterior en general, podemos agregar que ese tipo de representación de lo popular no excede ni aporta mayormente al tipo de discursividades que, a su vez, hemos encontrado en distintos momentos de la historia del cine nacional.

Lo que ocurre es que materialmente dificultada, por decir lo menos, y negada la posibilidad discursiva de un sujeto popular dotado de autonomía, capaz de articular desde sí mismo una visión y proyecto de sociedad y de su modernización, el discurso hegemónico recoge ciertos fragmentos y residuos de eso anterior y le construye un sentido global. Así, lo popular se manifiesta en dos direcciones: en un sentido plebeyo, es decir, como sumatoria de grupos e individuos pobres y necesitados y en tanto que masas consumidoras, en tanto aglomeración que incluso borra las clásicas distinciones entre sectores populares y medios.

A nivel de los medios y la industria cultural en general, es posible detectar, al menos, estereotipos que, de alguna manera, tratan de cubrir genéricamente dicho abigarrado conjunto. Uno muy importante es el del individuo o la familia popular, en tanto sujeto desvalido y sufriente. Las desigualdades y carencias reales permiten a la industria cultural y los medios apropiarse del lugar de vocero del sufrimiento popular, pero siempre en tanto drama individual. Lo anterior contrasta evidentemente con las imágenes provenientes del pasado y referidas a los movimientos sociales (sindicales, poblacionales, campesino, etc.) planteando y exigiendo derechos colectivos.

Una segunda forma en que lo popular aparece en los discursos hegemónicos establece alguna línea de continuidad con la figura que hace emerger la industria cultural en el siglo XX. Lo cómico y picaresco, expresado fundamentalmente en la TV y el cine recoge, a su vez, otros fragmentos, generalmente aquellos más vulgares, en el sentido estricto del término, es decir, los menos elaborados y cultivados por una experiencia de vida o de otro orden y supuestamente más cercanos a una aparente naturalidad. El humor televisivo de los últimos años nos ha mostrado un tipo de comedia de ese tipo, en que no hay ningún asomo de irreverencia ante ningún poder, una picaresca popular domesticada y limitada a un cierto rol en un libreto. No se trata de reproducir el escándalo de cierta elite intelectual ante la vulgaridad y la grosería, sino que de dar cuenta del empobrecimiento de una vertiente que por siglos en la cultura occidental y en nuestro país, desde el siglo XIX, permitió la manifestación de una cierta rebeldía popular, a través de la parodia, la burla y la risa (Salinas, 2005). En el caso del cine esta suerte de costumbrismo ha tenido algunas versiones un poco más elaboradas, como es el caso de la versión para cine de El Chacotero Sentimental y su segunda versión, Radio Corazón, o en Sexo con Amor.

Por otro lado, la tercera forma de manifestación de lo popular está asociada a la idea de la amenaza y el temor. Ya no se trata de la figura del roto alzado, a que aludimos antes, organizado en sindicatos o militante de partidos que, en tanto actor colectivo planteaba en su accionar la posibilidad -que a lo largo del siglo XX se fue haciendo cada vez más cercana- de remover las 
bases del poder de los sectores dominantes. La figura actual es una amenaza directa a los bienesy las personas, pero sin ninguna perspectiva más allá del beneficio individual de los agresores. Las pantallas televisivas están permanentemente mostrando la amenaza de la delincuencia sobre los barrios acomodados. Lo popular como amenaza también aparece ligado al narcotráfico y a la existencia de pandillas y bandas que asolan barrios y poblaciones. De esta forma, esta figura amenazante se liga a la primera, ya que una de sus víctimas son también los populares sufrientes.

Desde la instalación del sistema democrático liberal representativo en 1990, fue emergiendo en el discurso mediático el tema de la delincuencia y la seguridad, planteado como uno de los problemas más centrales de la vida nacional. En este plano, pareciera constatarse un éxito de estas estrategias. Tanto los estudios de opinión como el accionar de los partidos políticos han ratificado, de manera bastante tautológica, esta suerte de profecía autocumplida. Así, el fantasma que recorre Chile es el del sujeto delincuencial construido por las discursividades mediáticas, como principal amenaza a la convivencia y el orden, que asume los rostros del asaltante de casas, del ladrón callejero o en una versión más juvenil, el del vándalo infiltrado en manifestaciones sociales, culturales o políticas de la ciudadanía sana.

Una variante de lo anterior se encuentra en el cine chileno de estos años, por la vía de mostrar un actor popular semimarginal, cuya existencia oscila entre la delincuencia y el empleo informal e inestable. Se destaca allí una vida de carencias y abandono, de dificultades de acceso al mercado y la modernidad y, en general, una carencia de sentidos que vayan más allá de satisfacer necesidades inmediatas. Hay una larga lista de películas que van desde Caluga o Menta hasta Taxi para Tres y Mala Leche, pasando por Johnny Cien Pesos o La Fiebre del Loco. Las pocas tentativas de mostrar un sujeto popular colectivo en lucha por algunas de sus reivindicaciones han sido en una clave histórica pasada por el filtro de las necesidades de consolidación de las actuales hegemonías, como es el caso de Sub Terray Machuca, donde, al decir de Salinas y Stange, la despolitización de lo popular no asume el rasgo de sutileza que podría encontrarse en otras películas, sino que se verifica a través de un procedimiento que reduce a actores sociales reales a su condición de individuos sicológicos o morales, en tanto que personajes.

\section{- Referencias bibliográficas}

Estévez, A. (2005). Luz, cámara, transición. El rollo del cine chileno de 1993 al 2003. Santiago de Chile: Ediciones Radio Universidad de Chile.

Jara Donoso, E. (1994). Cine Mudo chileno. Santiago de Chile: CENECA-TEVECORP.

King,J. (1994). El carrete mágico. Una historia del cine latinoamericano. Bogotá: Tercer Mundo Editores.

Mouesca, J. (1997). El cine en Chile. Crónica en tres tiempos. Santiago de Chile: Planeta-Universidad Andrés Bello.

Mouesca, J.y Orellana, C. (1998). Cine y Memoria del siglo XX. Santiago de Chile: LOM.

Paranagua, P. A. (2003). Tradición y modernidad en el cine de América Latina. Madrid: Fondo de Cultura Económica. 
Rinke, S. (2002). Cultura de masas: reforma y nacionalismo en Chile 1910-1930. Santiago de Chile: DIBAM.

Romero, L. A. (1997). ¿Quéhacer con los pobres? Elites y sectores populares en Santiago de Chile, 1840-1895. Santiago de Chile: Sudamericana.

Salinas, C.y Stange,H.(2006). Estecine "chacotero" ... Imposturay desproblematizaciónen las representaciones del sujeto popular en el cine chileno 1997-2005. Universidad de Chile. Col. "Cuadernos ICEI".

Salinas, M. (2005). «Comida, música y humor. La desbordada vida popular». En: Historia de la vida privada en Chile. El Chile moderno de 1840 a 1925. Santiago de Chile: Taurus, pp. 85-118.

Santa Cruz, E. (1999). «El cine como picnic familiar». Revista Infraganti. №3.

Trejo, R. (2000). La industria audiovisual en Chile. Informe año 2000. Santiago de Chile: División de Cultura del Ministerio de Educación.

Vega, A. (1979). Re-Visión del cine chileno. Santiago de Chile: Aconcagua-CENECA.

Villarroel, M. (2005). La voz de los cineastas. Cine e identidad chilena en el umbral del milenio. Santiago de Chile: Cuarto Propio. 